\title{
IHTIKAR: PERILAKU MENIMBUN DALAM KAJIAN MUAMALAH
}

\author{
Taufiq ${ }^{1}$, Razali2 \\ ${ }^{1}$ Institut Agama Islam Negeri Lhokseumawe \\ e-mail: taufiqmahmud1979@gmail.com \\ 2 Institut Agama Islam Negeri Lhokseumawe \\ e-mail: razaliabdullah616@gmail.com
}

\begin{abstract}
\begin{tabular}{|l|l|l|}
\hline Diterima: 18-05--2020 & Direvisi: 31-05-2020 & Dipublish: 29-06-2020 \\
\hline
\end{tabular}
Abstract: Fiqh termed hoarding goods with the word ibtikar, various definitions were given by the jurists about Ibtikar. In the context of conventional economic Ibtikar synonymous with monopoly. Probibition of ibtikar in Islam in order to realize justice in the market between producers and consumers. There are three categories of ibtikar law in figh muamalah, which are haram, makhruh and may. Illat ibtikar incompetence is on goods that are needed by many people and becomes expensive if it is controlled by one party. Islam provides space for the government to intervene in the market so that the circulation of people's needs in the market takes place normally. Even in the study of siyasah muamalah, the jurists advocated the formation of the Hisbah to control the market mechanism in order to realize economic justice.
\end{abstract}

Kata kunci: ihtikar, perilaku menimbun, muamalah.

\section{PENDAHULUAN}

$\mathscr{P}$ enimbunan merupakan masalah yang selama ini masih menjadi persoalan dalam pertumbuhan ekonomi suatu Negara. Meskipun beragam kelompok dan lembaga dibentuk oleh pemerintah, namun belum memberikan jawaban yang memuaskan bagi masyarakat. Perilaku tersebut menjadi kendala bagi terciptanya ekonomi yang adil dan kesejahteraan yang merata.

Islam tidak membatasi seseorang berinovasi dan berinvovisasi dalam hal mencari dan mengembangkan harta miliknya, sebagaimana firman Allah QS al Baqarah [2]: 198

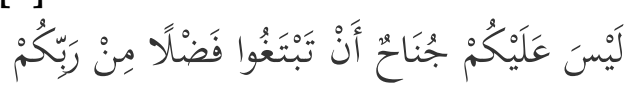

"Tidak ada dosa bagimu untuk mencari karunia (rezeki hasil perniagaan) dari Tuhanmu". (QS. Al-Baqarah [2]: 198)

Kebebasan yang diberikan tentunya memiliki batasan-batasan yang harus ditaati. Karena setiap model aktivitas yang dilakukan dalam dimensi muamalah memiliki ketentuan syara' begitu halnya dengan aktivitas menimbun barang, kaidah menyebutkan:

$$
\text { الأ صل فى الأفعال التقيد بالأحكام الشرعى }
$$

"Pada pokoknya segala aktivitas itu terkait dengan ketentuan-ketentuan syara'"

Dalam kajian fiqh muamalah, penimbunan mendapat perhatian khusus. Kitab-kitab fiqh klasik sudah menempatkan pembahsan khusus dalam BAB ihtikar. Karena hadis-hadis Rasulullah pun sudah menyebutkan larangan melakukan aktivitas tersebut.

Di dunia global, beragam istilah digunakan untuk penyebutan penimbunan, sesuai dengan konteks aktivitas yang dilakukan. Beragam penelitian yang telah dilakukan yang menunjukkan bahwa kedua perilaku tersebut memberikan dampak negatif yang sangat 
86

besar, terutama bagi pertumbuhan ekonomi.

\section{PENGERTIAN IHTIKAR}

Secara bahasa, kata ihtikar diambil dari al-hukr yang berarti az zulum wa al'is'ah al mu'asyarah adalah melakukan aniaya atau menzalimi. (Asy-Syrazi, 1398 H: 12; Munawir, 1994: 304; Zakaria, 2000: 60) Menjelaskan bahwa kata Ihtikar merupakan bentuk masdar sedangkan bentuk madhinya dapat dibaca hakira atau hakara, dalam mu'jam maqayis lughah kata hakara diartikan dengan al-habs (menahan), sedangkan hukara adalah menahan makanan sambil menunggu langkanya makanan tersebut. Ibnu Mandzur (Manzhur, n.d: 208) mengartikan kata hakara sebagai bentuk menyimpan makanan untuk diamankan. Dan kata ihtikar sebagai perbuatan mengumpulkan makanan dan barang yang dapat dimakan lainnya kemudian ditahan untuk menunggu waktu naiknya harga.

Dilihat dari pengertian Ihtikar secara etimologi sebagaimana disimpulkan oleh Moch. Bukhari Muslim (Muslim, 2010: 2) bahwa unsur utama ihtikar adalah menahan dan menyimpan (al-habs wa aliddikhar). Apabila tidak ada aspek ini, maka barang tersebut bukan dinamakan ihtikar. Sedangkan aspek lainnya seperti barang yang katagori obyek simpanan bukan menjadi aspek utama, akantetapi hanya menjadi bagian dari aspek tersebut.

Secara terminologi ihtikar bermakna penimbunan barang-barang yang akan dijual. Chairuman dan Sahrawardi (Chairuman Pasaribu, 2004: 47) menjelaskan bahwa katagori penimbunan bila barang yang dibeli dalam jumlah besar dengan maksud agar barang tersebut berkurang atau langka di pasar sehingga menyebabkan harga menjadi naik dan menjual kembali ketika harga naik akibat kelangkaan, dari perilaku tersebut akan diperoleh keuntungan berlipat. Makna barang dalam konteks ini sebagaimana dijelaskan oleh An Nabhani (Nabhani, 1985: 377) adalah sesuatu barang yang sangat dibutuhkan dalam kehidupan masyarakat dari segi sirkulasi pasar pada suatu masa tertentu kemudian sampai harga tersebut tinggi dan tidak stabil. Ketika barang tersebut sudah tinggi baru dikeluarkan untuk dipasarkan.

Para fuqaha memberikan definisi yang berbeda berkenaan dengan definisi ihtikar namun memiliki maksud yang sama.

Ulama Syafi'yah (Al-Khatib, n.d: 38) mendefinisikan ihtikar ialah menimbun sesuatu barang dan barang yang dalam masyarakat sangat dibutuhkan dengan maksud untuk mendapatkan laba atau untung yang banyak.

Definisi yang sama juga diberikan oleh ulama Malikiyah dan Hanabilah. Malikiyah (Al Baji, 1332 H: 15 ) menyebutkan ihtikar adalah menumpuk atau menimbun barang sebanyakbanyaknya tujuan dan maksud mencari keuntungan ketika di pasar tidak ada barang dan harga tidak stabil. Sedangkan Hanabilah (Sabiq, 1981: 162) ihtikar ialah membeli sesuatu barang yang barang tersebut sangat dibutuhkan di masyarakat dengan maksud untuk menimbun dan dijual kembali diketika barang tidak ada lagi di pasar agar mendapat untung yang banyak.

Makna ihtikar yang diberikan oleh Syafi'yah, Malikiyah dan Hanabilah yang tidak menyebutkan secara spesifik obyek yang berkaitan larangan ihtikar, namun ada penekanan pada barang yang sangat 
dibutuhkan (primer) sehingga melahirkan beragam interprestasi para pengikutya.

Berbeda definisi yang diberikan oleh Kasani (Kasani, n.d:) lebih spesifik berkenaan dengan makanan pokok. Ihtikar adalah membeli makanan pokok untuk menimbun ketika masyarakat sangat perlu, baru dikeluarkan.

Sayyid Sabiq (Sabiq, 1981: 162) ihtikar adalah membeli suatu barang dan menyimpannya agar barang tersebut berkurang di masyarakat sehingga harganya meningkat dan manusia mendapatkan kesulitan akibat kelangkaan dan mahalnya harga barang tersebut.

Ada juga fuqaha mendefinisikan ihtikar secara luas dan sempit. Fuqaha yang mendefinisikan secara luas atau umum di antaranya Abu Yusuf (yang bermazhab dengan Hanafi), dan mazhab Maliki. Para fuqaha tersebut menyatakan bahwa pembatasan larangan pada ihtikar bukan hanya terjadi pada objek pakaian, makanan dan hewan, tetapi seluruh bentuk barang yang menjadi kebutuhan dalam masyarakat banyak. Karena illat larangan ihtikar adalah aspek kemelaratan yang ditimbulkan bagi orang banyak. (Ad-Duraini, 1980: 85-86) Sesuai dengan kaidah:

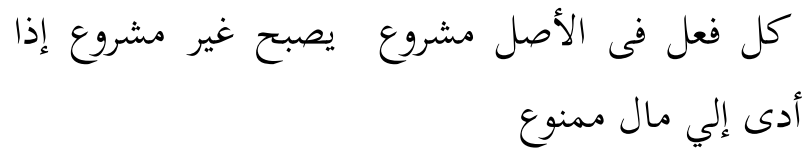

"Setiap perbuatan apada dasarnya dibolehkan (disyari'atkan), hukumnya boleh jadi tidak boleh jika membawa kepada sesuatu yang dilarang"

Kelompok fuqaha yang mendefinisikan ihtikar dalam kategori sempit yaitu terbatas pada makanan pokok, di antaranya Imam Al Ghazali dan sebahagian Mazhab Hanbali. Menurut mereka, persoalan ihtikar berkaitan dengan kebebasan pemilik barang untuk menjual barangnya. Maka larangan itu harus sebatas pada objek yang dimaksud oleh nash.

Meskipun ada perbedaan objek yang dikaitkan dengan perbuatan ihtikar, namun dapat disimpulkan bahwa ihtikar merupakan perbuatan menimbun barang untuk mencari keuntungan sehingga menyebabkan kelangkaan dan harga meningkat.

Ulama kontemporer Yusuf Al Qaradhawi memberikan pendapatnya bahwa ihtikar adalah menahan barang agar tidak berputar di pasar bahkan $\mathrm{Al}$ Qaradhawi berpendapat penguasaan barang secara transnasional (dari sektor hulu sampai ke hilir) bisa menimbulkan prilaku ihtikar karena dikuasai secara kelompok dan memiliki kekuasaan untuk menahan kapan diinginkan dengan memperhitungkan kondisi waktu (kebutuhan pasar). (Al-Qaradhawi, 2000: 189)

Ulama kontemporer lainnya yaitu Wabah az Zuhaili yang mendefinisikan ihtikar adalah kegiatan menimbun saat harga melambung, kemudian menjualnya dengan harga tinggi disaat barang tersebut dibutuhkan. Menurut Wabah az Zuhaili hanya barang yang berkaitan dengan makanan pokok saja yang dilarang karena barang selain makanan pokok tidak akan menimbulkan efek negatif terhadap masayarakat secara umum. (Zuhaili, 2010: 642)

Para Fuqaha menggunakan argumen dasar hukum yang digunakan tidak membolehkan ihtikar atau penimbunan barang adalah kandungan 
88

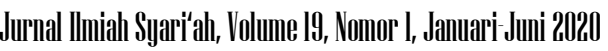

nilai-nilai universal Al-Qur'an yang menyatakan setiap perbuatan aniaya, termasuk didalamnya penimbunan barang diharamkan oleh agama Islam. (Karim, 2006: 52)

\section{PERILAKU IHTIKAR DALAM FIQH MUAMALAH}

Berkenaan dengan perilaku ihtikar dalam fiqh muamalah ada dua pendapat. Pertama, pendapat yang mengharamkan ihtikar. Golongan yang mengharamkan adalah jumhur Syafi'i, Maliki, Hanbali, Dzahiriyah dan Zaidiyah. Kedua, pendapat mengkatagorikan perilaku ihtikar dalam perbuatan yang dibenci (karahah). Golongan ini terdiri dari sebagian pengikut Syafi'i dan pengikut Hanafi. Namun pendapat kedua ini lebih pada persoalan perilaku ihtikar dalam hal makanan manusia. (Sulaiman, 2002: 13)

Berkenaan dengan sesuatu barang itu dianggap sebagai ihtikar, oleh karena itu, ulama terjadi khilaf pendapat. Sebagian ada yang menyatakan segala sesuatu barang yang bisa menyebabkan di pasar berpengaruh karena tidak stabil itu dianggap sebagai ihtikar. (Al-Syawkani, 1983: 337).

Sebagian ulama ada yang berpendapat, termasuk juga dalam ihtikar adalah hanya yang tergolong makanan pokoknya saja. Diantara ulama ada berpaham demikian ialah al-Ghazali (AlGhazali, 1967: 74-75). Bahwa yang dimaksud dengan ihtikar ialah hanya pada makanan pokok, sedangkan yang lain tidak dianggap dalam ihtikar. Sedangkan dalam hal penimbunan tidak ditentukan waktu, hanya pada batasannya saja ketika ia menimbulkan di pasar harga tidak stabil dan di pasar sudah gejolak itu dianggap sebagai ihtikâr.
Sebagian fuqaha (Mazhab Hanafi dan Mazhab Syafi'i) berpendapat yang diangap ihtikar adalah hanya berlaku barang kebutuhan sehari-hari yaitu kebutuhan primer, sedangkan barang kebutuhan lain atau sekunder tidak tergolong ke katagori ihtikar. Seperti pendapat An Nawawi dan Al Ghazali (AlGhazali, 1967: 92; Nawawi, 1995: 36) yang menyebutkan pelarangan ihktikar hanya pada makanan pokok saja. Hal ini didasari pada hadis Nabi Muhammad saw.;

قال رسول الله صلى الله عليه وسلّم: من احتكر طعاما أربعين ليلة فقد برىٔ من الله تعلى وبرئ الله منه (رواه

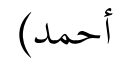

"Rasulullah SAW bersabda Barang siapa menimbun makanan dalam jangka empat puluh hari, maka ia sungguh lepas dari pada Allah dan Allah lepas dari padanya". (HR. Ahmad)

Sedangkan ada fuqaha (Mazhab Maliki serta sebagian ulama Mazhab Hanbali seperti Abu Yusuf dan Ibnu Abidin) yang berpendapat bahwa yang tergolong dalam praktik ihtikar ialah sesuatu bentuk barang yang ada kaitan dengan apa saja kebutuhan dalam masyarakat. Kebutuhan tersebut merupakan segala sesuatu yang menyebabkan kelangkaan atau keresahan dan bukan kebutuhan pokok saja adalah sebagaimana Hadis Nabi SAW:

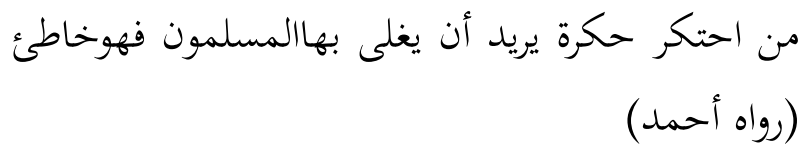

"Barangsiapa yang menimbun harta atau barang dengan maksud membuat kesusahan orang lain atau kaum muslimin maka dia adalah tercela". (HR. Ahmad) 
Dari hadis tersebut dapat dipahami bahwa yang termasuk sebagai menimbun barang ialah segala bentuk barang yang timbunannya dengan katagori barang yang umum. Sementara Imam al Syawkani (Al-Syawkani, 1983: 338) berpendapat bahwa yang menjadi pegangan pada ihtikar ialah 'illahnya, dalam arti bukan dari segi barangnya. 'Illahnya ialah dari segi menimbulkan karena bahaya bagi orang Muslim.

Umar bin al-Khathab, salah seorang dari sahabat Nabi Muhammad SAW., mengatakan ihtikar itu bukan hanya saja sebatas menimbun sesuatu barang, akantetapi barang tidak dijual sebagaimana yang ada kebiasaan di pasar atau menjual barang harga melebihi dengan harga di pasar setempat. Misalnya, apabila terjadi sebagian orang mempunyai sesuatu barang dagangan di pasar kemudian barang tersebut tidak dijual dengan harga yang layak sebagaimana biasanya, akan tetapi mereka menjual dengan harga mahal atau sangat tinggi, maka perbuatan demikian itu sudah dikatakan sebagai ihtikar. Umar juga mengatakan bahwa ihtikar bukan hanya berlaku dari segi makanan pokok saja dan hewan ternak, akantetapi setiap barang yang menyebabkan masyarakat menjadi susah dan langka karena barang tersebut tidak ada, seperti gula, minyak, pakaian dan lain sebagainya. Sedangkan batasan dianggap meresahkan bagi orang miskin anak yatim dan janda. (Qal'aji, 1981: 22)

Mengenai perselisihan pendapat ulama mengenai objek (barang) yang termasuk kategori ihtikar adalah sebagai berikut: Pertama, mazhab yang menyatakan bahwa ihtikar berlaku pada barang yang khusus yang dipakai untuk makanan saja. Sedangkan selain makanan tidak digolongkan ke dalam ihtikar. Pendapat ini didasari pada hadis tentang pelarangan pada ihtikar dalam segi makanan, yang berpendapat seperti ini ialah madzhab Hanafiyyah, sedangkan Syafi'iyyah mengkhususkan segala bentuk makanan yang dilarang untuk ditimbun ialah kurma, beras, dan makanan pokok.

Kedua, Madzhab yang menyatakan bahwa ihtikar hanya berlaku pada makanan dan juga pada pakaian. Alasannya ialah karena makanan dan juga pakaian merupakankebutuhan pokok kemudian sangat dibutuhkan oleh dalam kehidupan manusia. Ini pendapat madzhab Malikiyah.

Ketiga, Madzhab yang menyatakan bahwa ihtikar adalah sangat dilarang dalam Islam baik dari penjualannya atau dari segi pembeliannya. Pendapat ini adalah pendapat mazhab dhahiriyah.

Keempat, Madzhab yang menyatakan bahwa ihtikar segala bentuk jenis barang makanan ataupun barang lain. Selama aktivitas ihtikar yang dilakukan dapat merugikan manusia. Ini adalah madzhab yang sangat kuat dan merupakan ini Madzhab Abu Yusuf. (AlMasri, 1999: 139)

Perbedaan pendapat dikalangan fuqaha menurut Nasrun Haroen (Haroen, 2007: 164) lebih disebabkan pada pemahaman hadis-hadis ihtikar yang berstatus sebagai hadis ahad. Akan tetapi berdasarkan istiqra' (induksi) para ulama mengenai hukum ihtikar ditinjau dari ayat dan hadis, secara maknawi dalilnya adalah qathi'. Dan pemahaman seperti ini dalam rangka siyasah syar'iyyah (strategi menetapkan hukum). Hal ini sesuai dengan kaidah: 


$$
\begin{aligned}
& \text { كل فعل فى الأصل مشروع يصبح غير مشروع إذا أدى } \\
& \text { إلي مال ممنوع }
\end{aligned}
$$

"Setiap perbuatan apada dasarnya dibolehkan (disyari'atkan), hukumnya boleh jadi tidak boleh jika membawa kepada sesuatu yang dilarang".

Adiwarman A. Karim (Karim, 2014: 223) menjelaskan, bahwa suatu kegiatan ekonomi yang dapat dikatagorikan masuk dalam perilaku ihtikar adalah apabila salah satu tiga hal terpenuhi yaitu:

a. Berusaha adanya terjadi kelangkaan sesuatu barang baik dari segi menimbun sesuatu barang atau mengupayakan untuk masuk hambatan (entry barriers), supaya barang yang dibutuhkan sulit di pasar.

b. Menjual barang yang harga mahal dan lebih tinggi dibandingkan dengan harga sebelum terjadi kelangkaan.

c. Mengambil laba atau untung banyak dan lebih tinggi dibandingkan dengan untung yang diambil sebelum tindakan dilakukan.

Dalam pandangan penulis, jika merujuk kepada hadis yang diriwayatkan oleh Ahmad berkenaan perilaku ihtikar yang menimbulkan kesusahan bagi kaum muslimin, maka kaitan perilaku ihtikar dengan motif pelaku. Ini sesuai dengan kaidah:

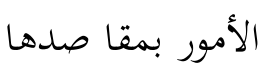

"setiap perkara tergantung pada maksudnya"

Motif atau sebab dilakukan suatu pekerjaan sangat menentukan dengan tujuan yang akan dicapai. Motif dalam fiqh muamalah dijadikan salah satu asas dalam bermualah yang diistilahkan dengan mabaadi al asbab (asas motiv atau sebab. Ini sesuai dengan hadis Nabi SAW.
Bahwa segala sesuatu tergantung kepada niatnya. Meskipun dalam tataran hukum sangat sulit dibuktikan. Namun bisa jadi sesuatu itu dilakukan karena keterpaksaan atau kebutuhan yang tidak bisa dihindari, setidaknya untuk menyelamatkan diri dan keluarga. Kaidah menyebutkan:

$$
\begin{array}{ll} 
& \text { رعا يةالضرورات والحاجات } \\
\begin{array}{l}
\text { "Memperhatikan } \\
\text { kebutuhan" }
\end{array} & \text { keterpaksaan dan }
\end{array}
$$

Berkaitan dengan maksud yang dipendamkan dalam hati itu merupakan domain bathiniyah (menyangkut persoalan yang tersembunyi dalam hati). Sehingga para ulama membuat kaidah:

$$
\text { الحاكم يتولى بالظواهر والله يتولى بالسرائر }
$$

"Hakim hanya menangani persoalanpersoalan yang nyata saja, sedangkan Allah akan menangani persoalan-persoalan yang tersembunyi (yang sebenarnya) dalam hati"

Pengharaman terhadap penimbunan barang apabila perbuatan terdapat tiga hal, yaitu:

a. Sesuatu barang yang akan ditimbun harus dibeli lebih dahulu.

b. Barang dibeli hanya bahan makanan yang sangat dibutuhkan oleh masyarakat.

c. Adanya kesulitan dalam masyarakat untuk mendapatkan sesuatu barang makanan yang sangat dibutuhkan. (Yusuf, 2009: 12)

Menurut Yusuf Qaradhawi penimbunan itu diharamkan jika memiliki kriteria sebagai berikut:

a. Dilakukan di sebuah tempat yang masyarakat penduduk di tempat tersebut akan kesulitan dan menderita karena adanya penimbunan. 
b. Tujuan dilakukan penimbunan hanya menaikkan harga barang sehingga kesulitan dan masyarakat susah mencari barang tersebut dan mereka menjual dengan keuntungan berlipat ganda. (Al-Qaradhawi, 2000: 358)

\section{DAMPAK IHTIKAR DALAM AKTIVITAS EKONOMI}

Dalam ekonomi Islam, ada terjadi beberapa aktivitas ekonomi yang hanya menguntungkan satu pihak saja namun aktivitas tersebut sangat dilarang bahkan diharamkan. Misalnya penipuan, khamar, riba dan perjudian, tadlis dalam jual beli dan parktik ihtikar. Larangan perilaku dalam ekonomi tersebut untuk menghindari terjadinya ketidakstabilan mekanisme pasar.

Secara keseluruhan ketidaksempurnaan pada pasar bisa terjadi karena ada tiga hal: Pertama, penyimpangan yang dilakukan secara terstruktur. Bila adanya prilaku persaingan tidak sehat yang dilakukan secara terstruktur dan sistematis. Hal ini akan menggangu mekanisme pasar. Seperti praktik monopoli, kompetisi di pasar yang tidak sehat dan lainnya. Struktur seperti ini yang dilarang dalam agama Islam, selain rusak pada sistem pasar juga sangat berlawanan dengan Islam yaitu maqashid al-syari'ah inilah yang menjadi sebab dilarang. Kedua, penyimpanan yang tidak terstruktur, adalah ada faktor internal atau temporer yang sangat mengganggu mekanisme pasar, misalnya ihtikar, tadlis, najasy dan kolusi pedagang tujuan membuat harga tidak stabil. Cara seperti ini sangat berlawanan dengan maksud yang telah ditetapkan syariat.
Ketiga, ketidaksempurnaan dalam informasi dan penyesuaiannya. Hal itu seperti apa yang terjadi membeli sesuatu barang dari produsen pas masih dalam perjalanan yaitu tengah jalan (bukan dalam pasar /talaqqi rukban), membeli barang dari orang bodoh dan tidak tau atau mengerti harga di pasar yang sebenarnya terjadi (al-ghubn).

Ketiga hal tersebut bisa merusak pasar ini harus dihindari dan sangat dilarang dalam agama Islam. Oleh karena demikian, setiap penjual dan juga pembeli harus hati-hati dalam melakukan praktik transaksi tersebut. Larangan yang sudah ada dalam agama memang ini tidak memberikan suatu sanksi yang tegas, tetapi sanksinya hanya berupa keharaman dari segi hukum, yang hal tersebut di akhirat perhitungkan.

Berkenaan dengan prilaku ihtikar dianggap sebagai kejahatan publik, karena dampak yang ditimbulkan terhadap masyarakat dari ihtikar tersebut. Maka data disimpulkan bahwa sanksi yang diberikan bagi pelaku ihtikar (muhtakir) jika dilihat dari perspektif Islam adalah ada dua cara yaitu $t a^{\prime \prime}$ dib (memberi peringatan), atau $t a^{\prime \prime} z i r$ (mempermalukan dan atau penghancuran pada barang dagangannya). (Fauzia Abdul Kadir, 2014: 209)

\section{SOLUSI MEMPERKECIL DAN MEMBERANTAS IHTIKAR}

Islam tidak membatasi intervensi Negara dalam mengatur permasalahan perekonomian agar masyarakat kebutuhannya cukup dan baik secara individunya maupun kelompok bisa terpenuhi secara menyeluruh atau 
proporsional. Prinsip-prinsip ekonomi dalam Islam berorientasikan kepada konsep falah yang bermuara pada sejahtera di dunia dan akhirat. Untuk itu konsep fiqh muamalah sangat dinamis menyesuaikan dengan keadaan dan kondisi masyarakat harus berorientasikan kepada kemaslahatan baik dalam proses pencapaian maupun kepuasan hasil yang ingin diperoleh, sebagai mana disebutkan dalam al-qawaid al-kulliyah. (Yusuf AlQardhawi, 2014: 7)

$$
\text { التخفيف والتيسير لاتشديد والتسير }
$$

"Memperingan dan mempermudah bukan memperberat dan mempersulit"

Dalam konteks Islam bahwa pemerintah memiliki kewajiban dalam melindungi hak-hak warganya termasuk bidang ekonomi agar terwujud keadilan dan kesejahteraan, hal ini didasari pada beberapa pedoman, yaitu:

1. Meningkatkan Konsep kekhalifahan. Sebagai wujud untuk meningkatkan kesejahteraan masyarakat dan keadilan itu merupakan tugas utama pemerintah yaitu amanah dari pada Allah SWT.

2. Konsekwensi dalam bentuk fardhu kifayah yaitu kewajiban kolektif. Merupakan kewajiban secara kolektif dan sosial yang terjadi dari mereka salah satu yang melakukannya.

3. Terjadinya unsur kegagalan dalam pasar yang menerapkan konsep alfalah, yaitu bisa mewujudkan ekonomi berbasis Islami ialah ada dalam kekuasaan pemerintah sebagai lembaga yang berkewajiban. (Azizya, 2004: 446)

Dalam tinjauan Islam negara wajib melindungi kepentingan rakyatnya dalam bentuk ketidakadilan baik yang dilakukan individu, secara kelompok, badan hukum maupun Negara yang lain. Begitu juga dalam hal jaminan sosial yang harus diperoleh warga Negara agar dapat hidup dengan layak dan bahagia. Oleh karena demikian, ialah sangat wajar apabila dalam UUD. 1945 menyatakan: (1), Sistem perekonomian disusun atas usaha semua berdasarkan asas kekeluargaan. (2), beberapa cabang produksi sangat penting bagi negara dan dalam kebutuhan kehidupan orang banyak serta dipegang oleh negara. (3), kemudian Bumi, air dan kekayaan alam ada didalamnya itu dikelola oleh Negara dan dimanfaatkan sebesarnya kepada kemakmuran seluruh rakyat.

Oleh sebab itu adalah menjadi sebuah wewenang negara dalam membuat sebuah peraturan yang sangat ketat bagi penimbun karena keperluan untuk semua. Hal itu berkaitan dalam sebuah kaidah:

$$
\text { تصرف الإمام على الرعية منوط بالمصلحة }
$$

"Tindakan pemerintah terhadap rakyat harus selalu berorientasi pada kemashlahatan orang banyak." (Al-Suyuthi, 1983: 83)

Oleh sebab itu, pemerintah harus turun tangan dan mengadakan pengawasan pasar. Pengawasan terhadap pasar tersebut agar dapat memberi jaminan kelangsungan mekanisme pasar sehat dan baik. Dalam Islam pengawasan tentang pasar didasarkan pada firman Allah SWT. QS. Ali Imran [3]: 110. Pengawasan pasar sudah dipraktikkan oleh Rasulullah SAW di antaranya adalah melakukan inspeksi kelapangan langsung ke pasar-pasar tujuan meninjau dan melihat dan mekanisme di pasar. Apabila terdapat tentang penetapan harga yang tidak sesuai sebagaimana mestinya di pasar, maka langsung Nabi menegur pelaku 
tersebut dan memberi arahan beserta nasehat bagaimana perilaku pasar yang baik.

Secara garis besar hisbah berfungsi: (1), Mengorganisasi dan mengontrol pasar supaya dapat memfungsikan sebagaimana mestinya dan menjadi solusi terhadap masalah ekonomi umat melalui mekanisme pasar sehat dan baik; (2) Menjamin instrumen harga barang dan jasa yang ditentukan hukum sesuai dengan hukum penawaran pasar dan hukum permintaan; (3) Melakukan pengawasan terhadap segala produk yang masuk ke dalam pasar; (4) Memberikan informasi mengenai harga di pasar dan tentang sistem pasar; (5) Menjamin tidak terjadi praktik monopoli di pasar oleh pelaku pasar setempat; (6) Mengawasi terjadi praktik pencaloan di pasar; (7) Mengupayakan etika Islami terutama apa saja berkaitan dengan mekanisme di pasar.

Dengan adanya hisbah, maka masyarakat di pasar bebas beroperasi dengan harga dan keuntungan yang ditentukan oleh kekuatan dari supply dan juga demand, tetapi boleh jadi pada saat bersamaan juga menjamin bahwa semua pranata sitem ekonomi telah melaksanakan semua kewajibannya dan telah sesuai aturan syariat. Apa saja tindakan dan pencegahan bisa dilakukan guna menjamin tidak terjadinya penipuan, kecurangan dan berbagai praktik lain yang dapat tidak stabil dan merusak sistem dalam pasar.

Tindakan yang bisa dilakukan oleh pemerintah ialah dengan menjual barang hasil dari timbunan dan harga sesuai harga pasar yang terjadi saat itu dan kalau ada keuntungannya dari penjualan tersebut, maka hasil penjualannya diinfaqkan atau disedekahkan pada orang yang membutuhkan atau fakir dan miskin. Sedangkan sipelaku ihtikâr cuma mendapatkan modalnya saja. Hal demikian dilakukan sebagai pembelajaran terhadap orang yang melakukan ihtikâr. Kemudian pemerintah memberikan peringatan atau teguran terhadap orang yang melakukan ihtikâr supaya tidak mengulangi dan melakukan perbuatannya lagi. Apabila tidak memperhatikan mereka terhadap teguran tersebut, pemerintah berwewenang memberi hukuman. Oleh karena demikan, negara merupakan pengatur regulasi dalam perdagangan mereka harus memberikan pengawas, pengaturan undang-undang atau peraturan-peraturan pemerintah lainnya untuk menstabilkan atau menertibkan mekanisme pasar sehingga bisa berjalan dengan baik.

Pemerintah punya hak untuk melakukan pengendalian harga di pasar, bila persoalan ditimbulkan oleh perilaku ihtikar yaitu dengan proses penetapan harga secara paksa (tas'ir jabari). Sikap pemerintah tersebut hanya dibatasi pada barang yang bersifat konsumtif. Sebagaimana definisi tas'ir jabari oleh Ibnu 'Urfah al Maliki (pakar fiqh Maliki):

$$
\text { تحديد الحاكم السوق لبايع المأكول }
$$

"Penetapan harga oleh pihak penguasa terhadap komuniti yang bersifat konsumtif".

Asy-Syaukani dalam kitabnya menjelaskan kewenangan penguasa / pemerintah dalam menyikapi terjadinya ihtikar: 
94



\section{KESIMPULAN}

Ihtikar merupakan aktivitas yang digolongkan sebagai kejahatan publik, baik dilakukan oleh individu maupun secaras kelembagaan. Dampak yang ditimbulkan dari kedua perilaku ini bukan hanya terhadap ekonomi tapi juga dapat berimbas kepada aspek kegiatan yang lain. Oleh sebab itu Islam sangat melarang bahkan memberikan sanksi berat bagi pelakunya. Salah satu dampak dari perilaku itu adalah bagi pertumbuhan perekonomian dan juga akan menghancurkan tatanan sosial kemasyarakatan.

Terlepas dari motiv dan objek yang ditimbun, para fuqaha bersepakat bahwa suatu perbuatan yang menimbulkan keresahan (kezaliman) bagi orang lain maka perilaku tersebut dihukumkan haram termasuk dalam perilaku melakukan penimbunan dengan objek apapun.

dilaksakan tidak terbuka, atau dengan menggunakan perusahaan yang sifatnya tidak boleh. Keempat, differensiasi pada harga kelompok usaha khusus yang bisa merugikan pihak lain. Kelima, dalam proses produksi tidak dijaga kualitas produknya, dan pengiklanan yang bisa merugikan pihak lain dan bersaing tidak sehat.

Keenam, menyampaikan dan memberikan informasi tentang produk beserta masalah pelayanan yang dapat menyesatkan kepentingan bagi konsumen. Pada Pasal 17 ayat 1, UndangUndang Nomor 5 tahun 1999 disebut, Para pengusaha sangat dilarang keras melakukan penguasaan terhadap produksi, distribusi, yang dapat menimbulkan terjadinya praktek monopoli dan usaha bersaing tidak bagus.

\section{DAFTAR PUSTAKA}

Ad-Duraini, F. (1980). al-Figh al-Islami alMuqarran Ma'a al-Mazahib. Damaskus: Mathba 'ah ath-Tharriyyin.

Al Baji. (1332 H). al-Muntaqa Syarah alMuwattha' (Juz. V). Bairut: Dar AlKitab Al-Arabi.

Al-Ghazali, A. H. (1967). Ihya' 'Ulumuddin (Jilid II). Mesir: Muasasah al Halabi wa ahu.

Al-Khatib, A.-S. (n.d.). Mughni al Muhtaj ila Ma'rifat Ma'ani al Fazh al Manhaj (Juz. II). Mathba'at Musthafa al-Bab al-Hanbali.

Al-Masri, R. Y. (1999). Ushul al-Iqtishadi alIslami. Jeddah: Dar Al Basyir. 
Al-Qaradhawi, Y. (2000). Halal Haram dalam Islam. Surabaya: Bina Ilmu.

Al-Suyuthi. (1983). Al-Ashbah Wa alNadzaair. Beirut: Daar al-Kutub AlIslami.

Al-Syawkani, M. I. 'Ali. (1983). Nayl al Awthar (Jilid V). Bairut: Dar al Fikr.

Asy-Syrazi, M. al D. M. I. Y. al F. A. (1398 H). al Qamus al Muhith (Juz II). Beirut: Dar al Fikr.

Azizya, A. Q. (2004). Membangun Pondasi Eknomi Umat. Yogyakarta: Pustaka Pelajar.

Chairuman Pasaribu, S. K. L. (2004). Hukum Perjanjian Islam. Jakarta: Sinar Grafika.

Fauzia Abdul Kadir, I. Y. (2014). Prinsip dasar Ekonomi Islam, Perspektif Maqashid al-Syari'ah. Jakarta: Prenada Media.

Haroen, N. (2007). Figh Muamalah (Cet. II). Jakarta: Gaya Media Pratama.

Karim, A. A. (2006). Ekonomi Islam Suatu Kajian Kontemporer. Jakarta: Gema Insani.

Karim, A. A. (2014). Ekonomi Mikro Islami. Jakarta: Rajawali Pers.

Kasani, "Ala ad-Din Abu Bakr Ibnu Mas"ud Al. (n.d.). Badai ash-Shana'i fi tartib al Syara'i (Juz. VI).

Manzhur, M. bin M. ibn. (n.d.). Lisan al Arab. (J. 4, Ed.). Bairut: Dar al-Shadir.
Munawir, A. warson. (1994). Kamus alMunawwi. Yogyakarta: Unit Pengadaan Buku Pondok Pesantren al-Munawwir.

Muslim, M. B. (2010). Ihtikar Dan Dampaknya Terhadap Dunia Ekonomi. Jurnal Studi Al-Qur'an, 6(1).

Nabhani, M. F. A. (1985). Al-Ittijah al Jama'i fi al Tasyri' al Iqtishadi al-Islami. Beirut: Muassasah al-Risalah.

Nawawi, A. (1995). Shahih Muslim bi Syarh an Nawawi (Juz XI). Beirut: Dar al Kutub al Ilmiyah.

Qal'aji, M. R. (1981). Mausu'ah Figh Umar Bin Khatab. Quwait: Maktabah AlFalah.

Sabiq, S. (1981). Fiqh as-Sunnah. Libanon: Dar al-Fiqh.

Sulaiman, S. S. (2002). Al-Wajiz fi Ahkam al $M u^{\prime} a m a l a t$. Mesir: Azhar University Press.

Yusuf, A. M. (2009). Bisnis Islami dan Kritik Atas Praktik Bisnis Ala Kapitalis. Penerjemah. Yahya Abdurrahman. Bogor: Al Azhar Press.

Yusuf Al-Qardhawi. (2014). 7 Kaidah Utama Fikih Muamalah. Jakarta: Pustaka Al-Kautsar.

Zakaria, A. H. I. F. I. (2000). Mu'jam Maqayis Lughah. Bairut: Dar al-Kutub.

Zuhaili, W. A. (2010). Fiqih Imam Syafi'i. Jakarta: Al Mahira. 